\title{
Engajamento e Resistência na Perspectiva de um Projeto Intercultural de Teatro
}

Beatriz Angela Vieira Cabral

Universidade do Estado de Santa Catarina

Universidade Federal de Santa Catarina

"Aquele que quer dar um longo salto deve estar preparado para dar alguns passos atrás. O hoje se sustenta através do ontem em direção ao amanhã ",

B. Brecht, Baal

"Na batalha com o velho as novas idéias chegam às suas formulações mais agudas" B. Brecht, Na Selva das Cidades

A oscilação entre engajamento e resistência foi uma constante durante o intercâmbio de pesquisa "Teatro - Escola - Comunidade", realizado entre as Universidades do Estado e Federal de Santa Catarina e a Universidade de Exeter/UK, patrocinado pela Capes e Conselho Britânico, no período de 1997 a 2001. O objetivo geral deste projeto de intercâmbio foi promover interesses comuns de pesquisa sobre o papel do teatro como elo de ligação entre a escola e a comunidade. ${ }^{1}$ Para tanto foram examinadas as possíveis contribuições do drama para o desenvolvimento de uma abordagem construtivista no ensino do teatro através de:

- Investigações relacionadas com o desenvolvimento conceitual na área do Drama como Pedagogia

Investigações de abordagens atuais para a formação do professor, relacionadas a inovações na prática de ensino em sala de aula, com foco na troca de experiências e observações viabilizadas pela análise conceitual mencionada acima. ramaspectos específicos e complementares ao fazer teatral em escolas

${ }^{1}$ Comunidade entendida aqui em seu sentido amplo, e não em relação a alguma abordagem específica, tal como teatro comunitário ou teatro para o desenvolvimento. 
e comunidades e as respectivas formas de formação de seus agentes. ${ }^{2}$

A análise das dimensões de engajamento e resistência aqui apresentadas referem- se à etapa conclusiva da parceria Beatriz Cabral - John Somers, realizada em Florianópolis entre março e abril de 2001, com a realização de um "Trânsito Teatral" na comunidade de Santo Antônio de Lisboa. Este trânsito se caracterizou pela montagem de cinco cenas teatrais concomitantes, cada uma construída e apresentada em um local do patrimônio histórico da comunidade, e baseada em fatos e/ou histórias vinculadas àquele local. Cada cena se repetiu cinco vezes, possibilitando assim, que os espectadores também divididos em cinco grupos, transitassem de uma cena à outra, liderados por contadores de histórias. $^{3}$

O projeto "Teatro em Trânsito" foi planejado pela equipe de pesquisa da área de Pedagogia do Teatro associada às duas universidades públicas de Santa Catarina, ${ }^{4}$ e as questões relacionadas com engajamento e resistência emergiram durante este planejamento, nas reuniões de trabalho com estudantes de licenciatura em teatro para identificação e definição de roteiros e ações, e finalmente, durante a construção das cenas e do trânsito na comunidade.

\section{As dimensões do entrelaçamento intercultural}

O papel do professor visitante foi inicialmente definido como "observador participante", e sua participação circunscrita aos encontros e debates com os respectivos grupos de pesquisa, entrevistas com os participantes das atividades e eventos observados, além de oficinas ofertadas pelo visitante aos alunos do professor anfitrião, em horário extra-classe ou extra-comunidade, i.e., fora da atividade-foco do intercâmbio.

\footnotetext{
${ }^{2}$ Os integrantes brasileiros deste intercâmbio foram: Beatriz Cabral (coordenadora - UDESC/ UFSC), André Carreira (UDESC), Gilka Girardello (UFSC), Ida Mara Freire (UFSC), Márcia Pompêo Nogueira (UDESC). Os integrantes da equipe inglesa foram: John Somers (coordenador), Geoff Fox, Linda Rolfe, Steve Cockett, e William Stanton, todos da Universidade de Exeter .$^{3}$ Esta forma teatral vem sendo por nós desenvolvida a partir de 1998, quando montamos "Plantas da Ilha - a História de Marina", ao longo de uma trilha no distrito da Lagoa da Conceição, Florianópolis (Cabral, 1998). Foram realisadas mais duas trilhas (Cabral, 1999), e cinco trânsitos (Cabral, 2000 e 2001), nomenclatura que adotamos a partir de 1999.

${ }^{4}$ Fizeram parte desta equipe no príodo 2000-2001: Beatriz Cabral (coordenadora), Célida Salume Mendonça, Maria Aparecida de Souza, Maria de Fátima Moretti, Zélia Sabino. A aluna Cláudia Regina Telles participou das reuniões de pesquisa referentes ao trabalho em Santo Antônio de Lisboa.
} 
Esta decisão foi tomada a fim de preservar as possíveis especificidades culturais dos trabalhos realizados e facilitar sua identificação e análise comparativa. Nos processos teatrais desenvolvidos como atividade-foco do intercâmbio a participação do visitante foi a de observador distanciado, e posterior retorno aos estudantes e grupo de pesquisa sobre sua percepção do evento, com ênfase nos momentos de estranhamento e resistência.

A presença de um observador de outra cultura, o foreign observer, revelou-se especialmente interessante nestes momentos de estranhamento, os quais deixaram transparecer as diferenças culturais e distintas visões de mundo, ajudando atores e professores a se auto-perceber e identificar.

A segunda dimensão do entrelaçamento cultural se deu através da interação universidade - comunidade. A comunidade que sediou esta experiência já havia realisado projetos em parceria com a universidade anteriormente, e se ressentia da falta de continuidade daqueles projetos ou de sua não participação nos benefícios posteriores. Esta circunstância, acredita-se, dificultou o envolvimento de moradores locais com o projeto.

Por outro lado, o patrimônio histórico desta comunidade, um dos primeiros assentamentos da Ilha de Santa Catarina, e um dos locais com maior número de sítios tombados da região, tem atraído grande número de visitantes, além de artistas e escritores que hoje lá moram.

Assim, a ambiguidade entre ressentimento e conhecimento das vantagens da popularização e divulgação das belezas e história do bairro, perpassou as interações entre os diversos coletivos interpretativos que participaram do evento. Se em decorrência das dificuldades de envolvimento inicial, duas das cenas tiveram os papéis principais representados por alunos da universidade, por outro lado, a problemática das relações entre os daqui e os de fora pôde ser incorporada às cenas históricas e deu origem aos focos de tensão necessários para o impacto da abordagem. ${ }^{5}$

Outro entrelaçamento, mais sutil quanto ao referencial básico para a realização do trabalho, porém complexo quanto à rede de interações, esteve presente nas relações entre coordenadora - demais integrantes da equipe de pesquisa - alunos-diretores de cena - alunos-atores.

A proposta para realização deste evento, suas características e abordagem, foram introduzidas pela coordenação, e resultaram de pesquisa sendo realizada desde 1996, quando teve início o planejamento do intercâmbio

\footnotetext{
${ }^{5}$ Para maior detalhes sobre o assunto ver meu artigo anterior, "Impacto e Risco em Teatro na Escola e na Comunidade”, Memória ABRACE V (Salvador, UFBA, 2002).
} 
e as visitas exploratórias realizadas pelos dois coordenadores ao país e universidade do colega estrangeiro. Assim sendo, a teoria e prática desenvolvidas no decorrer deste processo aconteceu em contextos diversos, incluindo-se aqui o inglês.

Por outro lado, o grupo de pesquisa sofreu alterações durante os cinco anos de realização do projeto, saída de alguns para capacitação, adesão de outros $^{6}$; assim, a relação engajamento - resistência esteve presente em todas as etapas do planejamento. A complexidade das interações ao nível do coletivo universitário foi ainda ampliada com a participação de alunos de várias turmas, orientados por diferentes professores.

Outro aspecto do entrelaçamento cultural ocorreu entre o elenco de cada uma das cenas. Este variou muito entre uma cena e outra: na do Engenho todos os atores eram da comunidade, com idades de 06 a 50 anos; a cena Curtume contou com cinco alunos, um adulto da comunidade, e cinco crianças; em Sobrado participaram nove alunos e doze moradores, incluídas algumas crianças; Intendência contou com dois alunos, dois pais de aluna, e doze adolescentes locais; Sineira, com quatro alunos e oito moradores. O número de diretores, em cada cena, variou de um a três. Os integrantes do grupo de pesquisa observaram os ensaios de todos os grupos, alternadamente, e trocaram opiniões com os diretores e elencos.

Além da variedade de origem, formação e idade, as cenas agregaram extratos sociais diversos da comunidade, conforme o tema e o local escolhidos, mas isto já exigiria um outro artigo e abordagem. Aqui serão feitas referências aos aspectos de interações culturais que incidiram sobre o engajamento e/ou resistência dos participantes com a abordagem do trânsito ou com as propostas de cena.

Entretanto, pode-se imaginar as interações entre os moradores da comunidade. Algumas referências espontâneas, da parte dos participantes, indicam início de amizades, interêsse despertado para novas montagens teatrais, encontros casuais. Maiores detalhes exigiriam uma pesquisa exploratória após o evento, com entrevistas e avaliações do significado da experiência para os diversos extratos da comunidade.

A dinâmica entre engajamento e resistência, ambos deflagrados por uma etapa anterior de envolvimento ou estranhamento, envolveu assim, áreas

${ }^{6}$ Deixaram de participar da pesquisa por motivo de capacitação, Maris Viana e Nara Micaela Wedekin; passaram a integrar a equipe no último ano, Célida Salume Mendonça e Maria Aparecida de Souza. 
de interesse e especialidade distintas, interações de trabalho entre alunos de fases distintas do curso de artes cênicas, rotatividade nas interações do grupo de pesquisa com os diferentes elencos.

\section{A relação engajamento - resistência}

O engajamento com uma atividade pressupõe empenho em sua realização; implica por-se a serviço de sua idéia e sua causa. Este conceito aponta para uma ação que vai além de um simples envolvimento, potencializando-o. A ação ou efeito de envolver-se com uma situação é considerada, por arte-educadores de diversas tendências, como sendo uma condição para a realização de trabalhos de expressão. A necessidade de enfatizar a participação com envolvimento é responsável, por exemplo, pela expressão já corrente na área.

Entretanto, não há como haver envolvimento sem emoção. A própria ação de cativar e atrair, inerentes ao processo de envolvimento, sugerem sua dimensão emocional. $\mathrm{O}$ ato de atrair ou cativar envolve uma recepção simultânea de sentimento e entendimento (cognição), pois o sentimento e a emoção não podem ser identificados independentemente de uma interpretação do objeto desta emoção. Como lembra David Best, a razão pode mudar o entendimento (de uma situação), e com ele, o sentimento em relação (a ela) ... Neste sentido, (também) o sentimento artístico, e as emoções a ele relacionados, são racionais em si, à medida que respondem à razão: estão sempre, em princípio, abertos à possibilidade de mudança, como consequência da reflexão, ou de razões oferecidas por alguém em favor de uma concepção diferente do objeto (ou situação) e a partir daí, a possibilidade de um novo sentimento sobre ele (ou ela). (Best, 1992:2)

Ao optar pelo termo engajamento, como uma forma de indicar o empenho do participante em uma atividade ou ação, decorrente da potencialização de seu envolvimento, pretende-se indicar a intensidade de seu envolvimento. Esta torna-se possível quando a sintonização com os contextos social e da ficção permitem que o participante possa experienciar aquilo que Janet Murray descreve como imersão:

... ele então se enterrou em seus livros e passou noites lendo do entardecer ao amanhecer, e dias, do amanhecer ao anoitecer (...) e ele penetrou tão profundamente em sua imaginação que acreditou 
que toda a fantasia lida era realidade, e ... decidiu ... tornar-se cavaleiro errante e viajar ao redor do mundo ...

Don Quixote de la Mancha

A história de Don Quijote, 150 anos após o descobrimento da imprensa, mostra o perigo do poder dos livros para criar um mundo mais real do que a realidade. Uma narrativa envolvente, em livros, cinema, teatro, pode ser experienciada como uma realidade virtual sempre que sintonizamos com a história com uma intensidade que possa obliterar o mundo a nossa volta. Histórias com tal poder evocam nossos medos e desejos mais profundos porque elas habitam o mundo mágico da fronteira.

Explorar os limites da fronteira entre ficção e realidade é a primeira condição para estabelecer formas interativas de participação em narrativas de ficção: Como entrar na narrativa sem destruí-la? Como ter certeza que as ações imaginárias não serão desenvolvidas no contexto real? Como viver a ficção sem ficar paralisado pela ansiedade? (Murray, 1997: 97-125).

A primeira condição para planejar a participação e imersão em situações de ficção reside na possibilidade de estruturar a narrativa, e delimitar seu contexto, de forma a antecipar e indiretamente indicar, as formas de interação desejáveis. Esta intervenção do professor/diretor ao nível da estruturação e delimitação da narrativa implica a identificação de possíveis ressonâncias com o contexto atual dos participantes; a previsão de papéis coletivos, oposições e confrontos; estabelecimento de uma ambientação e atmosfera propícias ao jogo cênico.

No espaço virtual, segundo Janet Murray, as estratégias e recursos responsáveis pela imersão dos participantes estão centrados na potencial expansão do sequenciamento e aprofundamento do repertório à disposição do navegador - o prazer de auto perceber-se como autor e agente de mudanças através de um repertório de opções aparentemente ilimitado (op. cit.). Esta tríade subjacente ao prazer de participar - amplo repertório, autoria e agente de transformação - aplica-se a qualquer processo criativo, virtual ou real, e seu reverso (ou outra face) conduz ao estranhamento. Resistência é indicador de um estranhamento mal resolvido. Como tal, revela uma reação ou resposta imediata a um engajamento prévio com uma ação, situação ou proposta. Resistência é assim caracterizada por um certo sentimento de perturbação, distúrbio ou choque, os quais, segundo Lyotard (1984:95-9) podem ser considerados como pré-requisito para qualquer tipo de mudança. Uma 
resistência, segundo o autor, aponta para a possibilidade de passagem da perturbação à reflexão; assim sendo, cabe ao artista (professor e/ou diretor) descobrir as formas pelas quais ele pode criar esta resistência.

Neste sentido, engajamento e resistência estão associados ao rompimento de expectativas quanto à narrativa, espaço, estilo, interações; ao cruzar as fronteiras do conhecido e à disponibilidade dos participantes para romper barreiras. Quanto maior o engajamento, maior as possibilidades de resistência, pois as mudanças irão incidir sobre aspectos de identificação mais claros e definidos.

Um outro ângulo por onde analisar esta questão é considerar a noção de resistência à imposição de significados reificados, e como tal, central àqueles que advogam uma pedagogia radical. Resistência à História, tal como esta chegou até nós; à dimensão simbólica dos espaços do patrimônio da comunidade; aos padrões teatrais vigentes; ao próprio texto teatral resultante das interações que o criaram. Esta não é apenas uma resistência no sentido político, mas sim uma resistência a qualquer transferência para a estrutura de poder em curso. Isto envolve problematizar a própria atividade de referência, jogando com a sua própria estrutura dialética de percepção: consciência versus inconsciência; ver versus olhar; simbólico versus imaginário - evidenciando a discrepância entre significante e significado, e a inadequação de rotular e definir categoricamente uma ação ou atitude. Resistir aos rótulos, fórmulas prontas, e definições, encoraja o reconhecimento daquilo que é marginal nas interações cênicas em andamento, e conduz a uma estética da experimentação, onde a arte explora o que não está dito, o que é sentido como ainda não percebido concretamente.

Engajamento e resistência, da forma analisada acima, foram acentuadas pela dimensão intercultural desta pesquisa: questionamentos sobre a distinção entre ficção e realidade, no sentido de identificar ações e atitudes, foram feitos não só pelo observador estrangeiro, mas também por participantes e espectadores (após o evento). A oscilação entre história e ficção foi acentuada pela interação entre os repertórios cultural (da comunidade) e artístico (apropriações por estudantes de teatro). Analogias, paródias e metáforas, responsáveis pela ressonância do espetáculo com o contexto real, e consequentemente, pelo engajamento com a proposta, foram estimuladas por apropriações e citações (ou 'cacos'); ao se basearem no repertório cultural foram sugeridos pela comunidade; ao se basearem no repertório artístico, foram introduzidos, em grande parte, por estudantes e professores de teatro.

Em decorrência das apropriações e colagens, a resistência foi estimulada pelos diversos coletivos interpretativos, sendo representada muitas vezes pelo 
embate entre pesquisador, diretor e atores. O pesquisador (coordenador e/ ou equipe de pesquisa) participou da pesquisa histórica, e do debate sobre as experiências anteriores e teorias subjacentes. Como tal, criou expectativas, e desenvolveu idéias próprias a respeito do desenvolvimento do processo e definição do produto. $\mathrm{O}(\mathrm{s})$ diretor(es) participaram da análise do roteiro e proposta de cena, e formaram sua concepção de montagem própria. $\mathrm{O}$ fato de sua participação ter sido caracterizada como estágio, na área de ensino do teatro, aumentou sua responsabilidade quanto à identificação de uma abordagem própria. Os atores da comunidade, eram os herdeiros históricos e 'proprietários' do espaço físico; possuíam assim idéias próprias sobre os eventos e personagens. Os atores visitantes (alunos), ao optarem por um personagem, o fizeram a partir de sua identificação com um determinado estilo de composição de personagem e expectativas de atuação. A complexidade sugerida por estas interações foi um desafio que gerou resistências múltiplas, mas também abriu portas para a análise e interpretação da experiência.

\section{Método de Investigação}

A abordagem etnográfica foi a opção de investigação durante este intercâmbio, uma vez que as aproximações entre os campos de conhecimento da Etnografia e do Drama estão refletidas tanto na linguagem quanto em suas categorias conceituais e áreas de debate.

Ambos os campos priorizam um relacionamento equilibrado entre processo e produto e partem do princípio que os processos artísticos são inerentes à prática da pesquisa e ensino em artes, considerando os aspectos estéticos e simbólicos em todas as etapas do processo. As implicações desta perspectiva são de especial importância para um trabalho artístico baseado na interação universidade - comunidade, pois exigem a sintonia do pesquisador com as qualidades particulares do contexto social e cultural onde o trabalho acontece, para que a compreensão dos textos social e performático dos participantes seja cumulativa através das diversas etapas da experiência, coleta de dados, análise e descrição.

O desenvolvimento deste processo de investigação, neste trabalho, esteve fortemente ancorado no conceito de pre-texto $^{l}$, que na área do Drama corresponde ao conceito antropológico de foreshadowed problems (antecipação de problemas), ambos usados para estabelecer expectativas, padrões, foco, sentido de direção, além de possibilitarem a geração de temas e ações. O pre- 
texto e seu equivalente antropológico apontam para o duplo papel do professor e/ou pesquisador, como participante e observador, insider e outsider, processo este que na área do teatro vem sendo designado como metaxis (pertencer a dois mundos simultaneamente). O duplo papel do professor e pesquisador, neste caso representado pelos integrantes do grupo de pesquisa, foi enfatizado nos diferentes níveis de interação desta experiência:

- entre universidade e comunidade - cada grupo integrando alunos de teatro e moradores do local, de diversas idades, ocupações e formação;

- entre o elenco de cada cena e o roteiro dramático criado pelo grupo de pesquisa - a forma de roteiro favoreceu a apropriação do texto pelos participantes, que o completaram e re-interpretaram, mesclando história e ficção de forma a atingir alguma ressonância com o momento atual;

- entre o texto teatral resultante das interações anteriores e os locais/espaços onde ocorreram as cenas - sejam estes aqueles em que os eventos ocorreram no passado, ou outros espaços urbanos ambientados cênicamente para revisitar a história da comunidade.

A metodologia utilizada incluiu detalhamento em processo, isto é, anotações pormenorizadas do processo de criação, ensaios e apresentação, seguidos de investigação das possíveis conexões (entre as cinco cenas) e padrões (ações e atitudes reiteradas por parte dos atores da comunidade). Por exemplo, como conexão observou-se que na maior parte das improvisações os temas 'discriminação' e 'os daqui versus os de fora” foram recorrentes. Como padrão, observou-se que a fala e o gestual do 'manezinho' (versão local do caipira) foram constantes. Entretanto, cada grupo lidou com estas questões à sua maneira e os resultados foram variados.

A necessidade de transformar os dados em texto expressivo e evocativo, comum tanto ao Drama quanto à Etnografia, ficou evidenciada nesta etapa da pesquisa, pelo recurso de poesia e cantorias, evocativas do contexto e situação dramática, tanto como entrada quanto como fechamento das cenas. O objetivo, porém, foi de ordem prática: ampliar a experiência interativa, ao estimular as dimensões emocional e estética, envolvendo os participantes e espectadores 
imaginativa e emocionalmente.

\section{O Trânsito "Santo Antônio de Lisboa na Virada do Milênio"}

Este trânsito, realizado nove meses após a versão inglesa "Payhembury Millenium Play"7, resultou em primeiro lugar, de uma análise pela equipe de pesquisa, da documentação referente ao processo inglês e da identificação do que nós faríamos diferente, a qual se baseou em três tipos de reflexão sobre as possíveis diferenças: as exigidas pelos contextos distintos, aquelas decorrentes de limitações de tempo, recursos humanos e materiais, e as relacionadas com as perspectivas estéticas, artísticas e educacionais dos pesquisadores.

O título do evento brasileiro procura mostrar de um lado, o parentesco com o irmão inglês - um resgate e recriação histórica de momentos significativos de uma comunidade; e por outro lado, salientar a orientação que conduziu o processo brasileiro: as cenas do passado seriam vistas com os olhos de hoje, em direção ao amanhã (parafraseando Brecht, em Baal).

Uma sinopse do registro histórico e das cenas é apresentada a seguir para melhor compreensão da análise.

\section{Curtume}

Registro Histórico: O local conhecido como 'curtume', denominação da atividade lá desenvolvida nos primeiros tempos da colonização de Santo Antônio, foi durante o final do século XIX e início do século XX a única fonte de água pública, não salobra, localizada no centro da Freguesia. Como tal, tornou-se o ponto de trabalho das lavadeiras, atividade acompanhada por muitas fofocas. A cena criada para representar este local e atividade foi ambientado em torno de 1880, a fim de incorporar a personagem histórica do Padre José Feliciano Pereira Serpa, vigário da comunidade durante 53 anos e conhecido por suas atividades em medicina popular, sendo famosas suas garrafadas e benzeduras.

\footnotetext{
${ }^{7}$ Pre-texto refere-se à fonte ou impulso que move o processo dramático, e indica a razão do trabalho ao conter o significado de um texto que existe anteriormente ao evento. Segundo Cecily O’Neill (1995) o processo dramático, mesmo quando baseado em improvisações, não ocorre em um vacuum: ativado por uma palavra, um gesto, uma imagem, um objeto (que podem ser considerados como estímulos) ele é entretanto definido e delimitado pelo pre-texto, que sugere a natureza dos eventos cabíveis em tal contexto e circunstâncias, e implica papéis, expectativas e tipos de ação.
} 
A Cena: O ponto de encontro das lavadeiras, antigo curtume, é o cenário da cena das lavadeiras, que disputam os tanques em meio a fofocas, anedotas e cantorias. A insatisfação e reclamações de uma delas, por não ter conseguido o tanque almejado, vira motivo de jacota das demais, quando uma das colegas sugere que a origem do mau humor deve-se, na realidade, ao baixo desempenho sexual do marido da colega insatisfeita. A acusação abre espaço para a introdução de histórias sobre as garrafadas do Cônego Serpa

\section{Sobrado}

Registro Histórico: D. Pedro II e sua comitiva aportaram em Santo Antônio em 21 de outubro de 1845, a bordo do vapor Imperatriz, como parte de visita protocolar. Após cerimônia na Igreja Matriz, onde foi entoado o hino Te-Deum Laudemus, foram entregues as honrarias às autoridades da Freguesia. O Padre Lourenço Rodrigues de Andrade foi vigário de Santo Antônio de 1797 a 1821, onde exerceu importante liderança política, sobretudo contra o Alvará Régio de 1785, de D. Maria I, A Louca, que mandou extinguir os teares no Brasil, para que nesta colônia não se fabricassem tecidos que viessem a competir com os preços daqueles fabricados em Portugal. Padre Lourenço passou então a se vestir com roupas feitas nos teares de Santo Antônio, assim se apresentando à Côrte. A junção destes dois momentos históricos visou salientar as contradições da relação colônia-côrte em períodos históricos anteriores, e sua possível analogia com outras épocas e locais.

A Cena: 1845 - D. Pedro II e numerosa comitiva visitam Santo Antônio. Durante a cerimônia de entregue de comendas às autoridades locais, realizada no local em que o evento ocorreu no passado, manifestantes vestidos com túnicas feitas em teares, aparecem sobre as ruínas das paredes do sobrado, bradando palavras de ordem contra o imperador e sua política à época. São feitas referências ao Padre Lourenço e ao Alvará Régio de D. Maria, e alusões ao fato de que as coisas não mudaram muito com a independência do Brasil.

\section{Engenho}

Registro Histórico: O registro da produção de farinha em Santo Antônio de Lisboa em 1797 aponta para 20.000 alqueires de mandioca, produção esta que começou a cair a partir de 1835 , com os efeitos da chamada farinha de guerra, por ser em grande parte enviada às tropas da Coroa no Rio Grande do 
Sul. A fabricação da farinha era acompanhada de muitos momentos de recreação, por exemplo, "as farinhadas", feitas no inverno quando a mandioca ainda estava bem consistente. Várias pessoas trabalhavam na farinhada, o forneiro, o cevador, o emprensador, e os raspadores de mandioca. Quanto maior o número de ajudantes, mais rápido terminava o serão. $\mathrm{Na}$ raspagem da mandioca gente de todas as idades contavam casos, cantavam quadrinhas e faziam desafios.

A Cena: A ação tem início durante uma raspagem de mandioca, onde os donos do engenho, parentes e vizinhos, entre cantorias e fofocas, revelam o contexto da produção e da vida no engenho naquele período. Os protagonistas, um jovem casal e o pai da noiva, discutem o repetido adiamento do casamento dos jovens, por falta de recursos, em decorrência do declínio da produção da farinha, devido aos sucessivos calotes do governo, que comprava a produção para alimentar as tropas e não pagava.

\section{Sineira}

Registro Histórico: Na década de 20, a limpeza e ornamentação da Igreja de Nossa Senhora das Necessidades de Santo Antônio de Lisboa estava a cargo de um grupo de senhoras do "Apostolado da Oração", associação recém fundada. Entre as histórias populares associadas à igreja está a de que o espaço situado entre a escada que leva aos sinos, e o cemitério aos fundos, incluindo-se aí uma das entradas laterais da igreja, era um local conhecido pelos encontros furtivos que lá aconteciam, devido à proteção que este lugar oferecia frente aos olhares dos passantes.

A Cena: a interação de personagens representando as senhoras do "Apostolado" e jovens daquela época foi o foco da cena. As distintas visões de mundo, por parte dos dois grupos, são confrontadas através do aparecimento em cena de uma figura mitológica do folclore local, "a maromba", que segundo alguns idosos da comunidade, entrevistados nesta pesquisa, era a caracterização usada por homens da época interessados em afastar os olhares do público de seus eventuais encontros amorosos.

\section{Intendência}

Registro Histórico: A eleição de 1947, com canditados do PSD e UDN, ficou na memória daqueles que dela participaram devido a um incidente com 
um eleitor embriagado (apesar da proibição da venda de bebidas alcólicas em dias de eleição). Segundo os entrevistados, o incidente ocorreu durante a visita dos presidentes dos dois partidos, que apareceram para inspecionar o andamento do pleito. Após acusações mútuas de compra de votos, o eleitor embriagado, irritado, declara seu voto. Os eleitores do partido oposto clamam pela impugnação, a qual não acontece, e o bêbado é retido até o final do pleito.

A Cena: uma paródia das atitudes, do gestual, e dos rituais eleitorais conduziu esta cena, que se baseou inteiramente em depoimentos de moradores que a vivenciaram, e nas anedotas que acentuam a persistência e atualidade dos antigos hábitos. A perspectiva crítica e o campo de reflexão foram abertos com a inclusão do poema "O Analfabeto Político", de Brecht, recitado por um eleitor bêbado e revolvado por ter sido impedido de votar. O bêbado perambula por entre os presentes, enquanto recita, tentando convencê-los de que há problemas mais sérios que o dele na condução do pleito.

Opções que delimitaram a seleção e reconstrução dos momentos históricos

Situações que tivessem ressonância com o contexto sóciopolítico atual, e permitissem que participantes e espectadores fizessem analogias com o presente.

- $\quad$ Possibilidade de recriar estas situações nos sítios históricos em que elas ocorreram no passado, procurando com esta recriação sugerir ou ressaltar a possibilidade de um novo olhar sobre o espaço e o evento que lá ocorreu.

- $\quad$ Fatos associados à mitologia local e/ou incluídos nas memórias dos idosos da comunidade, quer através das histórias que foram repassadas de pai para filho, quer através das anedotas construídas posteriormente.

Engajamento e resistência a partir da investigação etnográfica

A análise da oscilação engajamento - resistência aponta, em primeiro lugar, para o sentido de experimentação dos trabalhos realizados, e sua conseqüente caracterização como evento, em vez de espetáculo.

Este sentido de experimentação, reforçado pela mesclagem de histórias correntes na comunidade com fatos históricos, fez com que personagens e ações se situassem na intersecção das forças do social (histórico) e do psicológico (percepções pessoais - transhistórico). Além do imaginário coletivo, representado pelas histórias correntes na comunidade sobre os eventos passados, ficou clara a inclusão da interpretação particular dos eventos pelos atores que o representaram. Assim, na ausência de rubricas, e de uma análise mais detalhada 
da cena proposta pelos respectivos coletivos interpretativos (cada grupo), os atores tiveram um maior peso na identificação e escolha de seus personagens. isto ocorreu em maior grau nas cenas onde os atores eram a fonte das informações - adultos, da comunidade, entrevistados no início da pesquisa deste trânsito.

Em segundo lugar, o grande número de pessoas envolvidas exigiu a incorporação de figurantes ou 'jogadores' que interagiram com os atores de formas variadas: grupos familiares onde um dos participantes era o porta-voz do grupo; eleitores na sala de votação com a interação verbal centrada em dois atores; e outras cenas de multidão onde os figurantes atuaram apenas corporalmente ou em coro. A presença do coletivo influenciou a interpretação e recepção do texto teatral, de forma a produzir tanto o engajamento (coro, cantos), quanto o estranhamento (protestos, poema - por exemplo, "O analfabeto político", de Brecht, quebrou a comicidade de uma cena de compra de votos).

Finalmente, a estrutura dialética das cenas, que mesclaram ficção e realidade, e alternaram ou incluíram de forma implícita, real e imaginário, ação e narração; indivíduo e coro, acarretaram por vezes desencontros entre as unidades destes binômios, ampliando a oscilação. Por uma perspectiva mais ampla, pode-se dizer também que as distintas perspectivas dos pesquisadoresparceiros, quanto ao fazer teatro em escolas e comunidades; e suas próprias diferenças culturais refletidas na leitura e apreciação dos eventos teatrais em processo, provocaram momentos de inusitado angajamento (impacto e/ou entusiasmo) alternados com resistência e/ou rejeição.

Segundo a avaliação contínua realizada durante este projeto, a investigação das dimensões mencionadas acima foi privilegiada pelas formas interativas que caracterizaram a abordagem ao teatro em comunidade utilizada pelo teatro em trânsito. Ao enfatizar a expressão formas interativas em vez de formas de interação acentua-se a interatividade como um fator implícito às formas teatrais utilizadas, e não como resultante de uma experiência em determinado contexto e circunstâncias.

A forma adjetivada indica que as interações resultantes decorrem das estratégias utilizadas; não de eventos ocasionais. Este artigo remete assim aos recursos cênicos explorados no decorrer desta pesquisa, que constituíram a base do espetáculo em comunidade que encerrou o intercâmbio.

A identificação dos níveis de interação e das formas interativas utilizadas; bem como uma descrição sumária das cenas e seu argumento central, tornam-se necessários para focalizar e compreender as questões de engajamento 
e resistência percebidas durante o processo e as alternativas encontradas para orquestrar (selecionar e compatibilizar as formas de engajamento) ou contornar os problemas (de resistência).

\section{Formas Interativas de Teatro na Escola e/ou Comunidade}

A investigação e identificação de formas teatrais potencialmente interativas para trabalhos de curta duração baseados na relação universidade - comunidade, decorreu da necessidade da incorporação de pessoas sem experiência anterior em teatro, nas apresentações públicas resultantes de oficinas ou estágios realizados por alunos e/ou grupo de pesquisa. Estas apresentações, por sua vez, foram solicitadas pelos participantes, ávidos em compartilhar a experiência com amigos e familiares; e corresponderam ao entendimento, pelos atores, professores e pesquisadores, de que uma experiência teatral só se concretiza e adquire significância em seu contato com os espectadores. As formas interativas, desenvolvidas para a montagem do trânsito, adquiriram os seguintes contornos:

- Jogos de interação corpo - espaço/objetos. A escolha de espaços físicos relacionados com a memória histórica da comunidade facilitou a incorporação de atitudes e gestual típicos de personalidades da comunidade, e este jogo de espelho, observação e memória intensificou, por sua vez, a interação com o público

- Formas interativas de associar Fatos Históricos distintos - reunião de fatos, de momentos históricos diversos, relacionados com um mesmo aspecto da vida da comunidade - jogos de palavras e associações de imagens com ele relacionados; por exemplo, a visita de D. Pedro II e a atuação política de Pe Lourenço - expressões e imagens de eventos oficiais, protocolos, comemorações políticas e religiosas. A associação de fatos históricos ampliou a identificação dos participantes e espectadores com os eventos recriados. Além disso facilitou as analogias com o momento atual e a percepção de implicações e acontecimentos além da história oficial

- Formas interativas de associar História e Ficção - rodada de associações de imagens, conceitos e expressões, pela equipe de pesquisa, a fim de criar

criar um roteiro dramático associando momentos históricos e histórias populares, para ampliar a percepção dos hábitos, atitudes e contradições inerentes aos acontecimentos da comunidade. Por exemplo, associação da história da Igreja local com a história popular da maromba; ou dos fatos relaciona-dos 
com a vida do Cônego Serpa e os testemunhos, de idosos, sobre os hábitos das lavadeiras.

- Recursos de ambientação cênica: tochas, lamparinas, máscaras, etc., e sua associação com coro, palavras de ordem, rituais ...

Incorporação de danças, rituais, marchas, cortejos, passeatas, etc., orquestrados a fim de facilitar a incorporação de vinte a trinta atores e figurantes, e sua interação com os espectadores

- $\quad$ Limite de tempo e espaço - ênfase no ritmo, foco dramático e jogo cênico.

O potencial dramático das formas interativas do "Teatro em Trânsito" reside na possibilidade das histórias remeterem ao universo cotidiano, e o intensificarem para ampliar o engajamento dos participantes. As ações propostas, inseridas em formas ritualizadas ou jogos, são experienciadas simbolicamente - os participantes são protagonistas de uma ação simbólica, cuja trama segue uma das seguintes formas:

$\begin{array}{ll}\text { - } & \mathrm{O}(\mathrm{s}) \text { personagen(s) decifra(m) a narrativa } \\ \text { - } & \text { Unificam seus fragmentos } \\ \text { - } & \text { Assumem riscos } \\ \text { - } & \text { Enfrentam ou desafiam um antagonista difícil } \\ \text { - } & \text { Merrotam um sistema injusto } \\ \text { - } & \text { Alteram as regras do jogo }\end{array}$

A identificação de uma destas tramas, como base para as interações, facilita o planejamento das formas interativas mencionadas acima.

O potencial dramático é acentuado pela intervenção do professor ao nível da estrutura da atividade ou do jogo, isto é, ao estabelecer as regras do jogo e as condições nas quais os participantes irão interagir e criar, o professor está agindo como autor e intervindo no processo de criação. A intervenção do professor ao nível estrutural implica o estabelecimento das propriedades de uso dos objetos e a forma pela qual eles poderão interagir; como um coreógrafo ou co-autor, o professor cria um arsenal de possibilidades narrativas, suprindo ritmos, contexto e seqüência de jogos ou tarefas. 


\begin{abstract}
O intercâmbio só é possível como troca ou permuta, i.e., ao nivel da igualdade artística entre profissionais que se reonhecem mutuamente como companheiros de viagem
\end{abstract}

Richard Schechner ${ }^{1}$

Uma das implicações da prática antropofágica, centrada em empréstimos de outras culturas, é que metodologias, formas artísticas ou outros modelos, são sempre redefinidos; são incorporados às práticas e modelos nativos, usados de outra forma, observados a partir da perspectiva cultural de quem os adotou. Desta forma, a interpretação é sempre culturalmente específica.

Ao privilegiar, para efeito de pesquisa, a leitura do observador externo (estrangeiro), pretendeu-se questionar os empréstimos, associados à mudança de parâmetros de lugar, identidade, história e poder. Isto traz como consequência, implicações éticas de aquisição de diferentes códigos culturais, transparência nos processos de produção e recepção, aceitação e expressão das diferenças.

Quanto à aquisição de diferentes códigos culturais, sabe-se o teatro transmite significados não apenas através das falas e ações, e da concepção da montagem que juntos revelam a mensagem do(s) autor(es), mas também pela própria forma pela qual estes significados são transmitidos. No caso em pauta, a dimensão de evento, o número reduzido de ensaios, a base improvisacional da construção das cenas, e a própria forma de intervenção dos diretores, estimularam a busca de formas de expressão locais - favorecendo desta forma a leitura cultural das cenas, isto é, a naturalização das apropriações.

Além disso, aspectos formais do espetáculo, tais como: a diluição da fronteira entre os espaços da ficção e da realidade - espectadores incluídos no espaço da apresentação; o trânsito liderados por contadores de histórias - que desta forma carregaram o espaço teatralizado com eles durante o percurso entre uma cena e outra; e a inclusão de cantos/coros na abertura e fechamento de algumas cenas, propositadamente e de forma rudimentar, facilitando a adesão do público; levaram à percepção da montagem como evento, não como espetáculo.

À dimensão cultural do planejamento em si, e às características formais do trânsito, pode-se acrescentar a textualidade resultante da interação dos códigos culturais da comunidade, com as influências explícitas na formação

1 R. Schechner em entrevista a Patrice Pavis (1996) 
dos professores e alunos, e com a vivência com o professor visitante, para identificar os padrões estéticos desta proposta com a forma de mosaico, em substituição à tradicional linearidade. Com "transparência nos processos de produção e recepção", pretende-se salientar a viabilidade de abrir a concepção e opções de encenação à autoria múltipla (grupo de pesquisa e diretores de cena), ampliando assim o debate sobre as razões e implicações das escolhas e definições tomadas. Com isto pretende-se agilizar o desenvolvimento de uma estética teatral voltada a eventos de curta duração em escolas e comunidade, e com isto reduzir os riscos de resistência e ampliar as condições de engajamento.

Convém notar que o teatro é um fórum privilegiado para esta transparência, uma vez ser ela um pré-requisito do processo artístico - razões para a ação e a interação cênica são o ponto de partida para a construção do personagem e a delimitação do contexto e das circunstâncias a serem encenados.

Entretanto, a transparência traz à tona a questão da aceitação e expressão de diferenças. Contextos multiculturais e os novos meios de comunicação (ou a era da globalização?) causaram e reforçam uma cultura de opções - crescemos em meio a uma grande variedade de vozes culturais; é possível dizer que somos feitos de diferentes vozes, e como tal nos identificamos com aspectos de cada uma delas em momentos distintos de nossas vidas. Em vez de identidade, identificação torna-se o cerne do processo de aprendizagem; em vez de considerar a diferença como objeto de opressão, a noção de diferença democrática torna-se central à educação. Aprender a aceitar e expressar diferenças depende da transparência mencionada acima. Se as razões para uma determinada ação ou atitude não forem explicitadas, a aceitação das diferenças, a nível do debate intercultural, torna-se um discurso vazio; algo que fazemos por educação ou condescendência e não como resultado de nossa compreensão sensível de uma situação. Como afirma David Best, "as emoções são cognitivas em si, uma vez que são a expressão de um certo entendimento sobre seus objetos (...) os argumentos apresentados para a mudança de entendimento e avaliação de uma situação inevitavelmente envolvem uma mudança dos sentimentos em relação a estes objetos".

As implicações éticas pertinentes aos três pressupostos analisados acima foram acentuadas e evidenciadas através da participação ativa do observador estrangeiro. John Somers chegou em Florianópolis após a conclusão da etapa de identificação dos espaços físicos e construção do roteiro dramático, mas antes do início do semestre acadêmico, e portanto, antes do engajamento dos moradores de Santo Antônio de Lisboa e alunos de teatro. A presença do 
observador estrangeiro, na etapa de envolvimento dos atores, aumentou seu engajamento com o projeto. A atmosfera e a ambientação cênica

natural de Santo Antônio de Lisboa, seu casario e patrimônio histórico situado em estreita faixa de terra entre o mar e as montanhas, a chegada à noite com $\mathrm{o}$ ônibus especial que levava os estudantes logo após as aulas - tudo isso funcionou no âmbito do engajamento. Da parte dos estudantes e moradores, o fato de contarem com um inglês expert no assunto, interessado e disponível, estimulou a predisposição para envolvê-lo além da 'observação ativa'

Foi neste contexto que no final da primeira semana de trabalho na comunidade, alguns alunos anunciaram que John Somers faria o papel de D. Pedro II, na cena em que este visita Santo Antônio em 1845. Coube então à coordenadora, a função de resistência maior nesta experiência, uma vez que o projeto, além de propor que os personagens de destaque fossem representados pelas pessoas da comunidade, estava centrado na observação, pelo pesquisador visitante, das formas culturais específicas de construção de cena e personagens. Acrescente-se ainda, que para a equipe de pesquisa e alguns participantes, a opção de ter um inglês como imperador pareceu por demais simbólica, e criou outras resistências, ainda que não explícitas. Foi necessário então lembrar que a caracterização do observador como ativo, especificada no projeto, estava circunscrita à sua leitura das cenas e questionamento dos aspectos culturais que lhe causassem estranhamento, o que seria feito no transcorrer dos encontros contínuos de avaliação e/ou através de entrevistas a quaisquer dos participantes.

Se por um lado, o espaço aberto para que esta opção fosse sugerida pode ser considerado como um aspecto cultural importante da interação social brasileira, aqui específica a um projeto intercultural, sua concretização à nível de apresentação ao público, exigiria maior tempo de ensaios, para que a ironia subjacente ao fato (ou esta nova concepção de montagem) pudesse ser trabalhada, e o assunto debatido com a comunidade.

O episódio descrito acima, além de simbolizar um aspecto importante das discussões durante os cinco anos de intercâmbio com a Universidade de Exeter, revela a necessidade de uma vigilância permanente para conter o entusiasmo dos participantes em eventos desta natureza. Uma prática de teatro interativo, entre universidade e comunidade, exige um distanciamento mínimo e um grupo de referência para acompanhamento e avaliação contínua, além do suporte de um referencial teórico consistente. 


\section{Bibliografia}

BEST, David.1992. The Rationality of Feeling. London, The Falmer Press. CABRAL, Beatriz.1999. (Org.) Ensino do Teatro - experiências interculturais. Florianópolis, DAC/UFSC.

1998. "Drama como Método de Ensino", in Arte em Foco (Florianópolis, DAC/UFSC, Vol. 1, No 1, pp 38-77.

1999. "Teatro em Trânsito", in Memória ABRACE I - Anais do I Congresso Brasileiro de Pesquisa e Pós-Graduação em Artes Cênicas. São Paulo.

2001. "Ritual and Ethics - Structuring Participation in a Theatrical Mode", in Research in Drama Education (Oxford, Carfax Publishing Company.), Vol. 6, 01, pp 55-68.

COUNSELL, Colin. 1996. Signs of Performance - an introduction to Twentiethcentury theatre. London, Routledge, 1996.

GEERTZ, Clifford.1993. Local Knowledge. London, Fontana.

GIROUX, Henri. 1986. Teoria Crítica e Resistência em Educação. Petrópolis, Vozes.

1991. "Border Pedagogy and the Politics of Postmodernism", in Education and Society (James Nicholas Publishers.), Vol. 9, No 1, pp 23-38.

LYOTARD, Jean-François. 1984. The Postmodern Condition: A Report on Knowledge. Minneapolis, University of Minnesota.

MURRAY, Janet. 1997. Hamlet on the Holodeck - The Future of Narrative in Cyberspace. New York, The Free Press.

NEELANDS, Jonothan. 1996. "Reflections fram an Ivory Tower: Towards an Interactive Research Paradigm", in P.Taylor (Ed.) Researching

Drama and Arts Education - Paradigms \& Possibilities (London,

The Falmer Press.)

O’NEIL, Cecily. 1995. Drama Worlds. London, heinemann.

PAVIS, Patrice. 1996. The Intercultural Performance Reader. London, Routledge.

1992. Theatre at the Crossroads of Culture. London, Routledge.

SCHECHNER, Richard.1993. The Future of Ritual. New York, Routledge. TAYLOR, Philip. 1996. (Ed.) Researching Drama and Arts Education - Paradigms \&

Possibilities.London, The Falmer Press. 